\title{
A Comparative Study of Statutory Inheritance Between Chinese Mainland and Taiwan
}

\author{
Xiangxiu Wang \\ School of International Law \\ Shanghai University of Political Science and Law \\ Shanghai, China
}

\author{
Minhao Xia \\ School of International Law \\ Shanghai University of Political Science and Law \\ Shanghai, China
}

\begin{abstract}
With the deepening of the exchanges between Chinese mainland and Taiwan, economic and cultural exchanges have brought a series of property problems. At this time, the nuances in the settlement of inheritance disputes between the Chinese mainland and Taiwan have slowly emerged. Drawing on the advanced legislative system of the German and Japanese Civil Laws, the Taiwan Civil Code shows a more complete theoretical system in the links of people, things and affairs of statutory inheritance. The mainland's inheritance law has been continuously enriching its content and revising loopholes for more than 30 years since its establishment. Through the comparison and analysis of the scope, order, and share of relevant statutory heirs in Chinese mainland and Taiwan, we hope to make some contribution to the improvement of the inheritance system in the mainland's civil law.
\end{abstract}

Keywords-Taiwan; Chinese mainland; statutory inheritance; comparative analysis

\section{INTRODUCTION}

As we all know, "one country, two systems" is a powerful measure to maintain the harmonious development of Chinese mainland as well as Hong Kong, Macao and Taiwan. Due to the different historical backgrounds of development, the process and status quo of the development of the rule of law in the Chinese mainland and in Hong Kong, Macao, and Taiwan also show diversity. Since 2008, China has been committed to the peaceful development of relations between the mainland and Taiwan, and a series of agreements signed between the Chinese mainland and Taiwan have brought tangible benefits to the compatriots on both sides of the Strait. With the expansion of the exchanges between Chinese mainland and Taiwan, the living areas of people on both sides of the strait have become more intertwined, the cultural exchanges and learning, tourism, trade, and even marriage between people on on both sides of the strait have been increasing year by year, and the number of inheritance incidents of people in Chinese mainland and Taiwan is also rising. However, due to the existence of different legal systems in Chinese mainland and Taiwan, the unity of resolving such inheritance disputes has become a major problem. Compared with the civil law system of the mainland, the civil code in Taiwan is relatively more mature and shaped. Taiwan's legislation has largely borrowed from the German and Japanese law systems, and it also adheres to the spirit of the Three Principles of the People, the application of Taiwan' Civil Code has even further highlighted its all-encompassing coverage. In terms of inheritance, it is also more in line with the current social situation in Taiwan, so as to better resolve inheritance disputes in this region. After the founding of the People's Republic of China, the civil law system of Chinese mainland used the advanced civil law system for reference, and continued to develop and revise it in accordance with China's specific national conditions. It gradually develops and embodies the concept of the rule of law in socialist democratic politics with Chinese characteristics. Therefore, the mainland's inheritance law also has a good solution to the inheritance disputes in Chinese mainland.

The content of statutory inheritance includes many aspects This paper will specifically analyze the specific provisions of the mainland and Taiwan in terms of the scope, order and inheritance share of the heir.

\section{SCOPE OF HEIRS IN STATUTORY INHERITANCE}

\section{A. The Scope of Statutory Heirs in Chinese Mainland and Taiwan Is Similar}

1) Relevant regulations of mainland law: According to the provisions of Articles 10, 11 and 12 of the inheritance law in Chinese mainland, statutory heirs include: spouses, children, parents, brothers and sisters, grandparents, maternal grandparents, lineal descendants who inherit the subrogation, widowed daughters-in-law and sons-in-law who fulfill duty of support. From the analysis of kinship, the heirs in Chinese mainland are mainly the deceased's relatives by blood and by marriage; the lineal relatives by blood include children, lineal descendants, parents, grandparents, maternal grandparents, collateral relatives by blood include brothers and sisters, while spouses and widowed daughters-in-law and sons-in-law belong to lineal relatives by marriage.

The most important part of the inheritance in modern society is inheritance of property. ${ }^{1} \mathrm{We}$ believe that the various provisions of the law on heirs are intended to stipulate the degree of intimacy among relatives within the family through legal provisions; with the background of the deceased as the starting point and the family ethical concept of modern society,

Wang Geya: "On the Amendment of the Inheritance Law", China Legal Science, No. 6, 2013 
the family relationship category suitable for modern society is constructed, so as to achieve an appropriate inheritance system.

From the above aspect, the degree of intimacy of relatives by marriage is far weaker than that of relatives by blood to the deceased. ${ }^{2}$ From the scope of heirs, it is reasonable that relatives by marriage are less than relatives by blood. It is worth mentioning that in Article 12 of the inheritance law of Chinese mainland, the widowed daughters-in-law and sons-inlaw are listed separately. Although these two groups also belong to the scope of lineal relatives by marriage, it seems not in line with the understanding of ordinary people or rational people that they are taken as heirs; even there are no similar provisions in the laws of many other countries on this point. After carefully reading the law, it is not difficult to find that the mainland inheritance law has made strict restrictions on such heirs. Only those who fulfill the major duty of support can be listed as heirs. At the same time, the significance of this article is that it can help encourage widowed daughters-in-law and sons-in-law to support old people whose children have died, maintain stable family relationships, and build a harmonious social relationship. Some financial compensation is made to good daughters-in-law and sons-in-law after the old people die. ${ }^{3}$

In particular, Article 14 of the Inheritance Law stipulates that people other than heirs who depend on the support of the decedent for lack of ability to work and source of life, or support the decedent more, may be given heritage appropriately.

This does not stipulate the right of inheritance, but it redesignates the legal holder of part of the heritage. ${ }^{4}$ This takes into account the traditional Chinese virtues of respecting the elderly and cherishing the young, taking care of the elderly, the sick and the disabled; for protecting the legitimate rights and interests of women, children and the elderly is in accordance with the basic principles of the Chinese Constitution. From the aspect of property inheritance, it not only guarantees the protection of heirs who lack the ability to work and do not have a source of life, but also promotes the support of the elderly and minors, establishes sound family relationships, and maintains positive social relationships.

2) Legal provisions in Taiwan: In the civil code of Taiwan, the scope of heirs is stated in the Article 1138, Inheritance, 5th Section (statutory heirs and their order): Heirs, excluding their spouses, shall be determined in the following order: (1) Lineal descendants by blood. (2) Parents. (3) Brothers and sisters. (4) Grandparents. If the heir first in order defined in Article 1140 (inheritance by subrogation) and Article 1138 have died or lost their inheritance right before the commencement of inheritance, the lineal descendants by blood shall inherit their share by subrogation.

\footnotetext{
Chen Ying: "Analysis and Unfolding of the Essence of Inheritance Right", Law Science Magazine, No. 6, 2017.

Huang Tong: "Some Opinions on China's Legal Provisions of Relatives by Marriage", "Contemporary Law Review", No. 10, 2003.

Chen Ying: "Analysis and Unfolding of the Essence of Inheritance Right", Law Science Magazine, No. 6, 2017.
}

\section{B. Contrasting the Mainland Inheritance Law, Taiwan's Civil Code Has the Following Differences}

First of all, Taiwan's Civil Code contains a section of relatives. The meaning of lineal descendants by blood are equivalent to the concept of offsprings in traditional culture, namely all the direct descendants of the deceased. Conceptually, there are still differences from the "children" in Chinese mainland's regulations. Why? We feel that the provisions of Taiwan's Civil Code are designed to be consistent with the concept of heirs in inheritance by subrogation in Article 1140, and the entire inheritance section has used the concept of lineal descendants by blood.

Secondly, does the concept of grandparents mentioned in Article 1138 include the "maternal grandparents" mentioned in the mainland's inheritance law? We think the answer is yes. The grandparents and maternal grandfathers mentioned in the Mainland's inheritance law are all lineal relatives by blood of the deceased in the same generation in terms of relatives by blood, and the intimacy to the decedent is equally important generally speaking. If the parent of the decedent's father can inherit the property, the parent of the decedent's mother is also entitled to inherit. Therefore, the concept of grandparents in Taiwan should be interpreted as the parents' parents, including the father's parents and the mother's parents.

Thirdly, the legal inheritance rights for widowed daughters-in-law and sons-in-law are not stipulated in Taiwan. There will be a question here. Why is the difference between the provisions of the Chinese mainland and Taiwan? Inheritance rights are property rights enjoyed based on specific identities, which refer to the decedent's relatives by blood, while the spouse is a very special exception. Even if the spouse is a relative by marriage, he or she often accompanies the decedent in his/her her and gives birth to their lineal relatives by blood.

\section{Some Special Situations}

1) Fetal inheritance rights and remedies: Both the mainland and Taiwan recognize the legitimate inheritance rights of fetus.

Article 16 of the "General Principles of the Civil Law" of the Mainland: In terms of the protection of fetal interests, such as inheritance and acceptance of gifts, fetuses are deemed to have the capacity of civil rights. However, when the fetus is dead, his /her civil rights capacity does not exist from the beginning.

Article 7, general rules of Taiwan's Civil Code: Fetuses, if not died in the future, are deemed to have been born in terms of the protection of their personal interests. Paragraph 1, Article 1166, Inheritance Section: when the fetus is an heir, other heirs may not divide the heritage if his/her share is not retained.

There is no provision in the mainland's inheritance law that stipulates the inheritance rights of fetuses, but a separate provision was added to the General Provisions of Civil Law promulgated and implemented in October 2017, which established the inheritance rights of fetuses. Taiwan's Civil Code also stipulates the "personal interests" of fetuses in the 
general rules. Does the "personal interests" here include fetal inheritance rights? Article 1166 concerning the division of heritage provides an answer. This article shows from the side that the "personal interests" in the general rules include the legitimate inheritance rights of fetuses.

The greatest significance of the protection of fetal inheritance rights is to protect the legal rights of posthumous children. However, if it's difficult to judge the fetus's time of conception and the death time of the decedent, how can the fetus's inheritance rights be remedied at this time?

There is no provision for this in the civil law of the mainland. If this is the case in practice, the judge cannot invoke the law to reason or decide. In Taiwan, Article 1062, Family Section, Part VI, Civil Code, clearly specifies that the pregnancy period is from the 181 st to the 302 nd day before the child's birthday. For those who can prove that the pregnancy is traced back within the 181st day and the 302nd day in the above item, this period is taken as the pregnancy period. The conception of pregnancy period not only establishes the family relation, but also protects the inheritance rights of fetuses to a certain extent. It also reflects the degree of perfection of Taiwan's civil code system.

2) Inheritance rights for children born out of wedlock, adopted children and stepchildren with relationship of maintenance: Article 11 of the mainland's Inheritance Law stipulates that the children referred to in this Law include children born in wedlock, children born out of wedlock, adopted children, and stepchildren with relationship of maintenance. Obviously, Chinese mainland supports the inheritance rights of children born in wedlock and other children, and the degree of protection is the same.

On the other hand, the condition in Taiwan is a bit more complicated. First of all, the concept of children born in wedlock in Taiwan is slightly different from the mainland. Paragraph 1, Article 1063 of the Civil Code, stipulates that children of wives pregnant during the continuation of the marriage relationship are presumed as children born in wedlock. Therefore, only the children of wives pregnant during the continuation of the marriage relationship are presumed as children born in wedlock; otherwise the children are all children born out of wedlock. At the same time, however, Article 1065 of the Civil Code stipulates that the relationship between children born out of wedlock and their biological mother is regarded as children born in wedlock, that is to say, even children born out of wedlock may inherit the property of their biological mother. Under what circumstances can children born out of wedlock inherit the property of their biological father? Taiwan's Civil Code stipulates the permit system (Article 1064) and the system for father to claim children born out of wedlock (Article 1065). The permit system means that after biological father and the biological mother of the children born out of wedlock get married, the children born out of wedlock are regarded as the children born in wedlock. The significance of this system is to maintain a stable relationship between parents and children and the relevant legal rights and interests are also protected by law, including the inheritance rights of the children born in wedlock; the claim system is similar to it. The relation between parents and child is unilaterally recovered through the father's claim on the child. Relationship, even if the father is currently married. ${ }^{5}$ Secondly, Article 1077, Part VI, Taiwan Civil Code stipulates that the relationship between adopted children and adoptive parents and their relatives shall be the same as that of the children born in wedlock, unless otherwise provided by law. Taiwan's Civil Code stipulates adopted children's legal right of inheritance to adoptive parents, and also cuts off their rights of inheritance to biological parents; because Paragraph 2 of Article 1077 also stipulates the rights and obligations between adopted children and their biological parents and their relatives stop during the existence of adoption. However, when the husband or wife adopts the children of another party, the rights and obligations of the other party and their children are not affected by the adoption.

If the father or mother of the adopted child is married to another person, does the adopted child have the right to inherit the property of the married parents? Taiwan's law does not support the inheritance right under this circumstance. According to the analysis of Article 1075 and Paragraph 2, Article 1077 of the Civil Code, unless both the husband and wife adopt the child, the child cannot become the adopted child of the two. If the child is adopted by the adoptive father or a mother's spouse after they get married, the law does not recognize the adoption relationship of the latter. However, there is an exception that the adoptive father or mother's spouse is the biological parent of the adopted child. According to Paragraph 3, Article 1077 of the Civil Code, the adopted child can restore the parent-child relationship with the biological parents, that is, he/she can have the right to inherit the biological parents again. At this time, the adopted child has the right of inheritance to both parents based on the adoption relationship and the relationship of the child born in wedlock. Therefore, there are three situations in which adopted children have the inheritance rights: If the child is adopted jointly by a legal couple, then he/she can inherit all of the parent's property at the same time; if the child is initially adopted as the adoptive father or mother, but the adoptive father or mother has marries the biological parent of the adopted child, the adopted child can inherit the property shares of both parents; if the child is adopted separately, he/she can only inherit the adopter's property, even if the adopter marries the biological parent of non-adopted child. However, Taiwan's Civil Code does not stipulate the concept or the inheritance rights of step-children. Although there is no corresponding concept, step-children to their step-parent is equal to children born out of wedlock, so they cannot inherit the legal property of their step-parent.

3) Inheritance rights of adoptive parents and step-parents: Article 11 of the mainland's Inheritance Law stipulates that the parents referred to in this Law include biological parents, adoptive parents, and step-parents with relationship of maintenance; it is not difficult to see that the Chinese mainland recognizes the relationship between parents and children with actual relationship of maintenance, regardless of whether they are biological, adoptive or step parents and children. The mainland focuses on the equivalence of

Wang Liping: "An Exploration of the System of Claiming and Qualifying the Children Born out of Wedlock", in "The Jurist" 1997, No. 3. 
inheritance rights and support obligations; therefore, as long as there is an actual relationship of maintenance, parents and children can enjoy mutual inheritance rights.

In Taiwan, there is no explicit article in the Civil Code that stipulates the inheritance right under such circumstances, but the parent-child relationship is a mutual relationship. Combined with the deduction of inheritance rights for adoptive children and step-children in the previous section, we can also know the inheritance rights of adoptive parents and stepparents. The adoptive parents and children are considered to be parents and children, and both can inherit each other's property; step parents and children are generally unable to form parentchild relationships and lose their relationship of rights and obligations between parents and children, which also means that the step parent and children cannot inherit each other's property.

\section{THE ORDER OF STATUTORY HEIRS}

In statutory inheritance, the order of the heirs is directly related to whether the heir can obtain the share of the decedent's property or the how much the share is.

\section{A. Relevant Regulations of Mainland Laws}

According to Article 10 of the mainland's Inheritance Law, the first order is: spouse, children, and parents. The second order: brothers and sisters, grandparents, and maternal grandparents. After the inheritance starts, it is inherited by the heirs in the first order, and the heirs in the second order do not inherit. If there is no heir in the first order to inherit, the heirs in the second order inherit.

Compared with the inheritance relationship based on kinship relations in Taiwan, Chinese mainland considers the rationality of inheritance rights mainly from two aspects: the first is the closeness between kinship relations formed by marriage or blood, and the second is the equivalence between inheritance rights and support obligations and the degree of the supporting effects that actually occur in real life.

The mainland's inheritance law divides the heirs into two orders. These two different orders form an exclusive and supplementary relationship in the legal sense. That is, if there is a first-order heir, the inheritance rights of the second-order heir must be excluded, and if the first-order heirs do not exercise the inheritance rights, the second-order heirs can fill the gap and prevent the property from not being inherited. Therefore, the heirs in the second order can only fill the gap and have the right to participate in inheritance in three situations: there is no heir in the first order; there are heirs in the first order, but all give up the inheritance; there are heirs in the first order, but all lose their inheritance rights. However, in special circumstances, the second-order heirs may also not be restricted by the order of inheritance: Article 14 of the mainland's Inheritance Law stipulates that those who other than the heirs support the deceased a lot may be assigned appropriate inheritances. If the heirs in the second order are particularly obliged to fulfill the duty of support to the deceased, when the first-order heirs inherit the inheritance, they can obtain an appropriate part of the inheritance in accordance with the provisions of Article 14. In fact, this is not an actual inheritance right, because it is a compensation for the obligations fulfilled by people other than the heirs. ${ }^{6}$ From this we can see that the Chinese mainland attaches great importance to the equivalence of inheritance rights and the duty of support.

The first-order heirs (including spouses, children, parents) and second-order heirs (including brothers and sisters, grandparents, and maternal grandparents) stipulated in the mainland's inheritance law are in parallel order, which means that the heirs in the statutory order have equal inheritance rights without difference of sex and precedence. If there are several statutory heirs in the same order, the heirs share the undivided inheritance targets; when dividing, they equally share the inheritance target. Grandchildren are lineal descendants by blood, so they still enjoy the inheritance rights according to the provisions of inheritance by subrogation in Article 11t of the mainland's inheritance law, although they are not in the scope of the first-order heirs, and the Article 11 of the Inheritance Law stipulates that: If the children of the deceased die before the decedent, the lineal descendants by blood the decedent's children inherit by subrogation. The subrogated heir can generally only inherit the share of the heritage that their parent has the right to inherit.

For example: A has a spouse $\mathrm{B}$, they have a child $\mathrm{C}$ after marriage, and $\mathrm{C}$ has a daughter $\mathrm{E}$. A's father $\mathrm{D}$ is still alive. Now, C dies before A. According to the system of inheritance by subrogation: after A dies, E, as C's child of C, can be regarded as the first-order heir, and inherit A's heritage directly, but $\mathrm{E}$ can only inherit the heritage that $\mathrm{C}$ can inherit according to law. Therefore, the entire heritage of A will be inherited by the first-order heirs B (spouse), C (son), and D (father) jointly.

The second-order heirs: brothers and sisters, grandparents, maternal grandparents. Combined with the interpretation of brothers and sisters in Article 10 of the Inheritance Law, adopted children and natural children, adopted children and adopted children, form a relation of adopted brothers and sisters, who can be the heirs in the second order; but the relationship of rights and obligations between the adoptee and his/her biological brothers and sisters is extinguished upon the establishment of the adoption relationship, and cannot be second-order heirs; the step brothers and sisters with the support relationship can be the heirs in the second order. At the same time, only step brothers and sisters with the support relationship can be second-order heirs to each other. If the step brothers and sisters inherit each other's heritage, they can still inherit the heritage of their biological brothers and sisters the second-order heir.

\section{B. Provisions of Laws in Taiwan}

The order of heirs is determined in Taiwan in a way quite different from that of the mainland; Article 1132 of Taiwan's Civil Code stipulates that the heirs of inheritance, except spouses, are determined in the following order: (1) lineal descendants by blood, (2) parents, (3) brothers and sisters, (4) grandparents; Article 1139 stipulates that among the heirs in

\footnotetext{
Wu Guoping: "Legislative Construction of China's Heritage Retaining System", "Research on Rule of Law," No. 6, 2011.
} 
the first order as defined in the preceding article, close relatives rank first.

In Taiwan's civil code, the spouse is treated as a special heir who must have the inheritance right and is not included in the scope of the sequential heirs. The significance of this approach is to prove that the life companions that accompany every day and keep their oaths are the most intimate and strong relationship for the deceased, thus ensuring that the spouse can maintain a stable life when the other passes away and reducing family discord due to inheritance disputes.

In addition to spouses, Taiwan's Civil Code also classifies other heirs into four orders. Of course, like the principles of the mainland's inheritance law, the sequential heirs here are also in an exclusive and supplementary relationship; only if the heir in the previous order does not exist or abandons the inheritance right, the heir in the next order has the right to inherit. Sequential heirs will inherit all the property of the decedent together with the spouse of the decedent; there may be several sequential heirs, so the Civil Code also stipulates that heirs in the same order must equally share the property.

The lineal descendant by blood in the first order is a large concept. All the lineal descendants are possible to become heirs, but only the descendants with the closest blood relationship with the decedent will be designated as the firstorder heirs. However, the system of inheritance by subrogation makes it possible that even a close descendant heir may not be the sole heir. For example, the deceased has two sons B and C, $\mathrm{B}$ has a daughter, but $\mathrm{B}$ died before $\mathrm{A}$. According to the inheritance by subrogation, D can inherit the share that B can inherit by subrogation as a lineal descendant of B; therefore, D and $\mathrm{C}$ should be the first-order heirs.

Compared with the mainland's inheritance law, in terms of the inheritance by subrogation in Taiwan, the mainland limits subrogated heir to be children. However, Taiwan's civil code uses lineal descendants by blood. Although there is only a small difference in expression, this directly makes to Taiwan's system of inheritance by subrogation not limited by generation in principle; instead, the inheritance by subrogation in the mainland is limited to two generations. ${ }^{7}$

There is a big difference between the Chinese mainland and Taiwan in terms of sequential heirs: the mainland's inheritance law lists parents as the first-order heirs; although Taiwan lists them as the second-order heirs, the parents are actually rank after spouses and lineal descendants, in the third order. Why is there such a difference?

We believe that there are two reasons. Firstly, the situation on both sides of Straits is not the same. For a long time, the mainland has persisted in its national policy of family planning and giving a good birth and good care, which has led directly to the fact that mainland families have only one child for a long period of time. The mainland's inheritance law was implemented in 1985, and family planning was written into the constitution as early as in 1982. The inheritance law ranks parents as the first-order heirs, so that parents can have certain

Chen Wei, Ran Qiyu: “Thinking on Perfecting the Legislation for Scope and Order of Statutory Heirs in China”. Legal Forum, No.2, 2013. assets to protect their lives in old age, and to some extent reduce the pressure of support for young people. Compared with the mainland, Taiwan's social security system has relatively complete institutional guarantees; there is both the government's economic and material support and the support and care of descendants. Secondly, the civil code of Taiwan retains the main content of the 1930 "Civil Law of the Republic of China", which learned from the most advanced German civil code of the time, forming an advantageous feature of all-inclusive. The most pure inheritance is retained in the section of inheritance, passing on everything of predecessors to future generations, continuing to complete the legacy of predecessors and bearing the responsibility of continuous innovation.

\section{DETERMINE THE SHARE OF HERITAGE}

Determining the share of heritage is a crucial step in the process of handling inheritance disputes. The impartiality and persuasiveness of share allocation directly determine the effectiveness of conflict resolution.

\section{A. Relevant Regulations of Mainland Law}

There is also a certain discrepancy between the Chinese mainland and the Taiwan region in determining the inheritor's share in the distribution of heritage. Chinese mainland law has not made too many provisions on this issue, but only adheres to the context of the socialist rule of law. Paragraph1, Article 13 of the mainland's Inheritance Law stipulates that under normal circumstances, the equality of statutory heir's inheritance share should be respected. Although the equality of inheritance share is not compulsive, the legal rights of all statutory heirs must be protected, so that the distribution ratio is relatively balanced. Of course, specific statutory heirs should be analyzed concretely according to specific situations. Legal provides have flexible clauses that for vulnerable individuals or individuals with outstanding contributions in family relations, such as heirs who have special difficulties in their lives and have lost some abilities to work, or who are have fulfilled the major duty of support to deceased, or who have lived with the deceased while he/she was alive, Paragraph 2, Article 13 of the Inheritance Law stipulates that the above two types of statutory heirs should be given this larger share of heritage as appropriate according to their own specific circumstances on the premise of equal distribution of inherited property. In contrast, heirs who have not fulfilled family members' responsibilities can also be appropriately reduced in their share. For instance, Paragraph 3, Article 13 of the Inheritance Law stipulates that heirs who have the ability and condition to support fail to fulfill their duty within the scope of duty to support shall be reduced in their share of heritage before the inheritance in accordance with the severity of their conduct. In serious cases, the heirs may not even gain any share of the heritage. ${ }^{8}$

At the same time, in the field of China's civil law, the principle of autonomy of will persists. On this basis, the mainland's inheritance law also has provisions stipulating that:

\footnotetext{
$8 \quad$ Yang Lixin: "Opinions on Amending the Ten Issues of the 'Inheritance Law”,, "Law Application", No. 8, 2012.
} 
if the heirs agree on a consensus, they may propose to distribute the heritage in accordance with their own autonomy. At this time, the share that the statutory heirs can inherit may be unequal. The above-mentioned share allocation plan is discussed under the premise that the heirs are the statutory heirs. For those candidates who are not included in the scope of statutory inheritance, the mainland law has also formulated separate legal provisions according to corresponding conditions to protect their rights. Those who are other than heirs but depend on deceased due to lack of labor ability, and those who are not listed into heirs but offer more care to the deceased while he/she was alive, can also obtain a part of the property.

\section{B. Provisions of Laws in Taiwan}

The Civil Code of the Taiwan region has undergone several amendments, of which the regulations on inheritance share are mainly reflected in Articles 1141 and 1144 of the Civil Code. Article 1141 stipulates that when there are multiple heirs in the same order, they should divide and inherit the property equally according to the number of people, unless otherwise clearly provided in the law.

In view of the difference in the order of statutory heirs between Taiwan and the provisions of China's mainland laws, the Civil Code in Taiwan also has specific provisions on how to divide property in detail. Article 1144 of Taiwan's Civil Code stipulates that if there is no specific situation under the law that causes the deceased's spouse to lose inheritance rights, no matter how many heirs the decreased had, no matter how the order of heirs is, the deceased's spouse always enjoys the inheritance right. Only when other heirs in different orders exist, the share of their spouse's inherited rights can vary. Article 1138 of Taiwan's Civil Code stipulates that, apart from spouses, other heirs must be ordered in lineal descendants by blood, parents, brothers and sister, and grandparents. If the spouse inherits together with heirs in the first order, ie, the lineal descendants by blood, the share of inheritance among the heirs should be evenly distributed according to the number of people. In this case, the distribution method fully complies with the provisions of Article 1141. If there is no heir in the first order, the deceased's property will be extended from the heirs in the first order to the heirs in the second order. When the spouse inherits together with the heirs in the second order, ie, the deceased's parents, regardless of the number of heirs in the second order, the spouse can directly inherit $1 / 2$ property of the decedent, and the remaining $1 / 2$ of the property is divided equally by the heirs in the second order according to the number of people. If there is no heir in the first and second orders, then the spouse inherits together with the heirs in the third order, ie, the brothers and sisters of the decedent, at this time, the inheritance share of the spouse is the same as that of the conditions of heirs in the second order, which means he/she can inherit half of the property separately. Next, if there is no heir in the first, second and third orders, then the spouse inherits together with the heirs in the fourth order, he/she will obtain a greater share of the property, that is, the spouse acquires $2 / 3$ of all property, and the remaining $1 / 3$ of the property is divided equally among the grandparents as the fourth-order heirs. Of course, the above situation is the distribution of shares in inheritance when the spouse and the heirs in the respective orders inherit the property at the same time. If only the spouse is the heir to the property, the spouse should obtain all the property of the decedent. If the decedent had no legal spouse at the time of his/her death, the property should be equally divided among other statutory heirs according to the number of people. At this time, the allocation of shares of the property is the general rule of Article 1141 of the Civil Code.

It can be seen from the comparison that the concept of distribution of property shares in the Chinese mainland and the Taiwan region is still very different. The inheritance law of the mainland is within the scope of statutory inheritance, and it prefers to balance the rights and interests of the statutory heirs of all parties and tries to ensure that the statutory heirs who enjoy the inheritance right can enjoy the right to inherit property with little or no discrepancy. The inheritance share of individual statutory heirs with special circumstances will be determined by the judge with discretion according to different situations. ${ }^{9}$ It can be seen that the inheritance law in China emphasizes the equality of inheritance rights and duty of support in the statutory distribution process, and there is a balance between the rights obtained and the duties fulfilled.

Of course, for those subjects that cannot obtain certain compensation strictly according to the law, considering that they took care of the deceased while he/she was alive based on the traditional Chinese virtues, special articles are made for rewarding them. This virtually promotes the establishment and cultivation of the traditional national spirit of the Chinese people to a certain extent. However, on the other hand, it can be known from the regulations on statutory inheritance share in the civil code of the Taiwan region that the inheritance right of the legal spouse at the death time of the decedent has been protected to a greater extent. This also highlights the importance of kinship in Taiwan. It also helps to maintain the unity of a family, and it's also a great comfort to the spouse of the deceased after a mishap occurs to a family. The inheritance share remaining statutory heirs is correspondingly reduced based on their closeness from the decedent, but the heirs in the same order still adhere to the most basic principle of distribution, i.e. equal distribution. This also reflects from the side the fact that Taiwan's civil law extends the core spirit of the Three Principles of People.

\section{CONCLUSION}

Through the above-mentioned comparison and analysis, it can be clearly seen that in addition to the similarity in individual provisions, Chinese the mainland and the Taiwan region also reflect the difference in the concept in different degrees in the provisions of such issues. Backed by different social status quo and historical development, it is difficult for the two regions to have completely identical views and arguments on the same inheritance issue. ${ }^{10}$ However, it is

9 Yang Lixin, He Lijun: "Reconsideration of Retaining System in China's Inheritance Law," "Journal of the National Prosecutors College", No. 4, 2013.

10 Chen Wei: "Monograph of relative law and inheritance law", Law Press, 2009, p. 15. 
precisely because of the existence of such differences that will objectively impel us to further strengthen the collision between the Chinese mainland and the Taiwan region on the individual issues and other issues that will be revealed in the future development of the rule of law. Although the establishment of a universal legal system is a method that can be considered to thoroughly solve the problem of regional differentiation, such differences cannot be completely assimilated in a short period of time. Therefore, we should take a more sensible attitude toward the different provisions between the mainland and Taiwan. We must admit that Taiwan has presented a more perfect state in the compilation and revision of the civil law system than in the civil law system in the mainland; as a civil law system with a shorter application time, the civil law system in Chinese mainland still needs some time to perfect itself. Under the guidance of the concept of "one country, two systems", the civil law in Chinese mainland should develop based on actual national conditions, learn from others' strong points to offset its weakness, and draw lessons from the advanced concepts of the rule of law in each region. With the accumulation and enrichment of experience, in the process of perfecting the socialist legal system, it also affects the transformation and convergence of the legal system in other regions. Under the joint promotion of the Central People's Government and regional governments, Chinese mainland and Taiwan will achieve regulatory integration within the region, and eventually reach a beautiful scene of common prosperity across the country.

\section{REFERENCES}

[1] Chen Wei. Monograph of relative law and inheritance law [M]. Beijing: Law Press, 2009.

[2] Yang Lixin. Opinions on Amending the Ten Issues of the "Inheritance Law"[J]. Legal Forum, 2012(8).

[3] Chen Wei, Ran Qiyu. Thinking on Perfecting the Legislation for Scope and Order of Statutory Heirs in China [J]. Legal Forum,2013(2).

[4] Wang Liming, Wu Handong. New Theory of Civil Law [M]. Beijing: China Renmin University Press, 2014.

[5] Yang Lixin. Research on Legislation of Inheritance Section of Specific Provisions of the Civil Law [J]. China Legal Science1, 2017(4). 